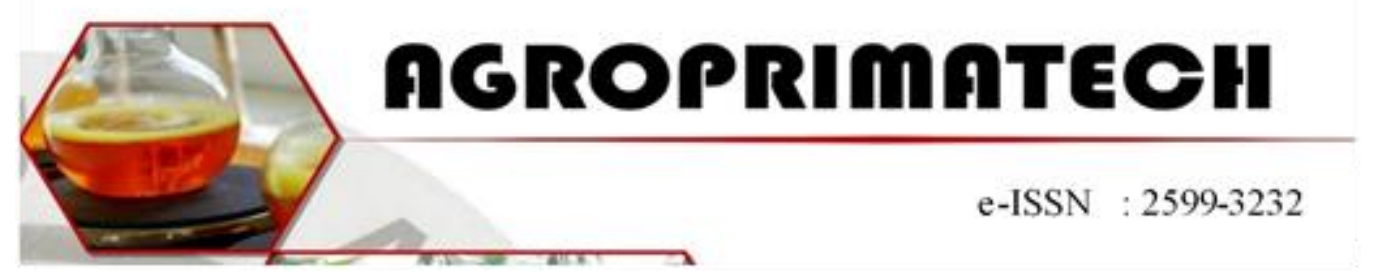

\title{
STUDI MORFOMETRIK IKAN PIMPIANG DI SUNGAI KUMU DESA RAMBAH KABUPATEN ROKAN HULU PROVINSI RIAU
}

\author{
ARIEF ANTHONIUS PURNAMA ${ }^{1}$, DAHLIA, ETI MEIRINA BRAHMANA², NUR AINUN \\ BR HASIBUAN ${ }^{2}$ \\ 1,2 Fakultas Keguruan dan IImu Pendidikan Universitas Pasir Pengaraian \\ Email: ariefanthoniuspurnama@gmail.com
}

\begin{abstract}
ABSTRAK
Penelitian tentang kajian morfometrik ikan pimpiang di Sungai Kumu Desa Rambah Kecamatan Rambah Hilir Kabupaten Rokan Hulu Provinsi Riau ini telah dilakukan dari bulan November 2018 sampai Januari 2019. Bertujuan untuk mengetahui keragaman jenis ikan dan karakter morfologi dari ikan pimpiang. Penelitian ini menggunakan metode survei dengan teknik pencuplikan sampel secara purposive sampling. Proses pengukuran karakter morfologi ikan pimpiang dengan menggunakan jangka sorong. Penelitian ini menemukan 15 individu ikan pimpiang yang terdiri dari 2 spesies. Berdasarkan penelitian yang telah dilakukan pada tiga stasiun penelitian bahwa ratarata karakter morfologi Oxygaster anomalura dan Parachela oxygastroides memperlihatkan sedikit variasi. Karakter morfologi Oxygaster anomalura memiliki kisaran panjang total 105,37-164,05 $\mathrm{mm}$ dengan rata-rata $\pm 128,23 \mathrm{~mm}$, dan tinggi badan 15,14-32,89 $\mathrm{mm}$ dengan rata-rata $\pm 22,40 \mathrm{~mm}$. Sedangkan karakter morfologi Parachela oxygastroides memiliki kisaran panjang total 105,27-119,60 mm dengan rata-rata $\pm 113,14 \mathrm{~mm}$, dan tinggi badan $21,13-24,93 \mathrm{~mm}$ dengan rata-rata $\pm 22,93 \mathrm{~mm}$.
\end{abstract}

Kata kunci: Ikan Pimpiang, Karakter, Morfologi, Sungai Kumu

\begin{abstract}
The research about characters morphological of glass fish in Kumu River Rambah village Rambah Hilir district Rokan Hulu regence has been conducted from November 2018 to January 2019. This research aims to know the diversity of fish and the morfology character of glass fish. The proces in morphology character of glass fish measurement used a calipers. This study founded 15 individual glass fish consisting of two species. Based on what has been done in three research station, it is found out the Oxygaster anomalura and Parachela oxygastroides. Oxygaster anomalura morphological character has the total length range $105,37-164,05 \mathrm{~mm}$ with average \pm $128,23 \mathrm{~mm}$, and body height $15,14-32,89 \mathrm{~mm}$ with average $\pm 22,40 \mathrm{~mm}$. While morphological character Parachela oxygastroides has the total length range105,27$119,60 \mathrm{~mm}$ with average $\pm 113,14 \mathrm{~mm}$, and body height $21,13-24,93 \mathrm{~mm}$ with average $\pm 22,93 \mathrm{~mm}$
\end{abstract}


Keywords : Glass fish, morphological character, kumu river

PENDAHULUAN

Indonesia merupakan negara kedua tertinggi keanekaragaman hayati nya setelah Brazil di Amerika Latin. Dalam bidang perikanan Indonesia mempunyai keanekaragaman hayati yang hidup di laut dan perairan air tawar. Terdapat 3000 jenis ikan yang ditemukan di berbagai perairan, dimana 1300 jenis ikan yang hidup di perairan tawar di Indonesia (Kementrian Kelautan dan Perikanan, 2012: 1). Ikan (Pisces) merupakan salah satu kelas hewan vertebrata yang hidup di air yang mempunyai insang dan sirip (Nelson, 2006: 2). Salah satu habitat ikan pada ekosistem perairan tawar adalah sungai. Sungai merupakan wilayah yang dilalui air yang bergerak dari tempat tinggi ke tempat yang rendah baik melalui permukaan atau bawah tanah (Nursyahra, 2012: 3).

Ikan pimpiang merupakan salah satu ikan yang berperan sebagai pengendali ekosistem sungai misalnya dalam proses rantai makanan. Kelangsungan hidup ikan sangat tergantung dari kondisi perairan tempat hidupnya (Rudiyanti dan Astri, 2009: 40).

Ikan pimpiang merupakan ikan yang termasuk ke dalam Filum Chordata, Kelas Actinopterygii, Ordo Cypriniformes, Famili Cyprinidae dan terdapat 3 genus. (Kottelat dkk., 1993: 45-56). Famili ikan Cyprinidae merupakan ikan air tawar yang sangat besar dan tersebar hampir diseluruh penjuru dunia kecuali Australia, Madagaskar, Selandia Baru dan Amerika Selatan (Kottelat dkk., 1993: 34). Salah satu cara untuk mengetahui spesies dari suatu ikan adalah dengan mengamati karakter morfologi yang bertujuan untuk mengetahui keragaman jenis ikan dan juga untuk mengetahui perbedaan karakter marfologi dari kerabat dekatnya.

Identifikasi ikan secara morfologi mengacu pada kajian morfometrik dan meristrik. Budiharjo (2001: 107-108) menjelaskan Morfometrik adalah karakter yang dapat diukur pada bagianbagian tubuh ikan misalnya panjang total, panjang standar dan panjang kepala. Sedangkan, karakter meristik merupakan perhitungan bagian tertentu pada tubuh ikan, misalnya jumlah jari-jari sirip ikan dan jumlah sisik linea lateralis.

Sungai Kumu merupakan sungai yang mengalir di sepanjang Desa Rambah Kecamatan Rambah Hilir dan bermuara menuju sungai Batang Lubuh. Lebar sungai mencapai 6-8 meter dengan panjang sungai mencapai $10 \mathrm{~km}$. Sungai ini merupakan salah satu perairan yang digunakan oleh masyarakat setempat untuk berbagai keperluan mandi, cuci dan kakus (MCK).

Sungai Kumu termasuk sungai yang diduga telah tercemar, ditandai dengan aktifvitas yang dilakukan warga di sekitar sungai Kumu berupa pembuangan limbah rumah tangga, adanya penebangan hutan dan pengalihan lahan untuk perkebunan kelapa sawit menyebabkan salah satu penyebab tercemarnya sungai Kumu. Dengan kondisi sungai semakin tercemar dan adanya nilai ekonomi ikan pimpiang dikhawatirkan akan berpengaruh terhadap jumlah spesies ikan pimpiangyang terdapat di sungai Kumu.

Sedangkan, informasi mengenai jumlah spesies dan karakter ikan pimpiang masih sangat kurang. Hal ini terlihat belum adanya penelitian mengenai karakter morfologi ikan Pimpiang di wilayah Provinsi Riau. Tujuan penelitian ini adalah untuk mengetahui karakter morfologi ikan pimpiang di Sungai Kumu Desa Rambah Kecamatan Rambah Hilir Kabupaten Rokan Hulu Provinsi Riau.

\section{BAHAN DAN METODE}

Penelitian ini telah dilaksanakan pada bulan November 2018 sampai dengan Januari 2019 di perairan Sungai Kumu, Desa Rambah, Rambah Hilir, Pasir Pengaraian, Rokan Hulu, Riau, 
kemudian dilanjutkan di Laboratorium Pendidikan Biologi, Program Studi Pendidikan Biologi, Fakultas Keguruan dan IImu Pendidikan, Universitas Pasir Pengaraian. Dengan menggunakan metode survei dimana sampel dicuplik secara purposive sampling. Penelitian kajian karakter morfologi menggunakan metode experiment. Pengambilan sampel dilakukan dengan tiga kali pengulangan pada masing-masing stasiun dengan titiik koordinat yaitu stasiun 1 pada bagian hulu (koordinat 0055'47.52" N $100^{\circ} 19^{\prime} 24.17^{\prime \prime}$ E). Stasiun 2 pada bagian tengah

(koordinat 0055'55.95" N 100²0'13.34" E). Stasiun 3 pada bagian muara (koordinat $\left.00^{\circ} 55^{\prime} 51.49 " \quad N \quad 100^{\circ} 20^{\prime} 43.81 " \quad E\right)$. Peralatan yang digunakan adalah jaring insang dengan panjang $\pm 10 \mathrm{~m}$, lebar 1 $m$ serta ukuran mata jaring 1 inchi dan $3 / 4$ inchi, jala tebar berjari-jari $2,7 \mathrm{~m}$ dengan ukuran mata jala 1 inchi, tangguk, pancing, meteran, botol sampel, kamera digital, alat tulis, jangka sorong dengan kesalahan bacaan 0,05 $\mathrm{mm}$ atau rol (penggaris) dengan ketelitian $0,1 \mathrm{~cm}$, lup, termometer, baskom, talam, bola tenis meja, stopwatch dan GPS (Global Positioning System). Sedangkan bahan yang digunakan adalah alkohol $70 \%$, indikator $\mathrm{pH}$ universal, sarung tangan, pancang, tali rafia, masker dan kertas label.

Pengambilan sampel ikan dilakukan pada masing-masing stasiun penelitian dengan 3 kali pengulangan setiap stasiun dan 3 kali pengambilan sampel dengan menggunakan jaring insang, jala tebar, tangguk dan pancing. Pemasangan jaring insang dilakukan pada pagi hari sampai sore, jaring dipasang pada badan sungai dengan cara tegak lurus dengan arah arus, kemudian diarahkan sepanjang $100 \mathrm{~m}$ menuju jaring. Penangkapan sampel ikan dibantu oleh dua orang dengan menggunakan jaring insang dan dua orang dengan menggunakan jala tebar, selain itu untuk melengkapi ikan sampel dikumpulkan juga ikan dari hasil tangkap dengan menggunakan alat tangkap tangguk dan pancing.

Kegiatan penangkapan ikan sampel ini dilakukan tiga kali seminggu untuk satu stasiun. Sampel ikan yang didapat dimasukkan ke dalam plastik yang berisi air kemudian didokumentasikan, selanjutnya ikan diberi label dengan menggunakan kertas label yang berisi nama lokal ikan, nomor urut sampel (kode), lokasi dan tanggal koleksi. Kemudian jumlah individu yang ditemukan dihitung dan dikoleksi pada botol sampel yang diberi alkohol $70 \%$.

Selanjutnya sampel dibawa ke Laboratorium Pendidikan Biologi, Program Studi Pendidikan Biologi, Fakultas Keguruan dan IImu Pendidikan Universitas Pasir Pengaraian, untuk diidentifikasi masing-masing spesies dengan menggunakan buku panduan Identifikasi ikan Freshwater fishes of Wester Indonesia and Sulawesi, karangan Kottelat dkk. (1993). Pada setiap stasiun penelitian dilakukan pengukuran faktor fisika dan kimia antara lain suhu, $\mathrm{pH}$, kedalaman, kecepatan arus. Setelah diidentifikasi ikan sampel akan disimpan dalam larutan alkohol $70 \%$, untuk dijadikan sebagai koleksi di Laboratorium Biologi, Fakultas Keguruan dan IImu Pendidikan, Universitas Pasir Pengaraian. Kajian karakter morfologi ikan Pimpiang dapat dilihat pada gambar 2 berikut.

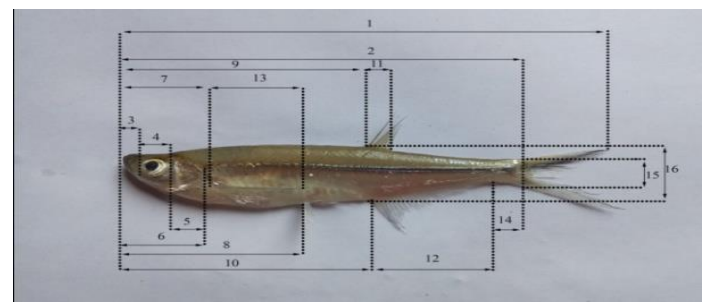

(a)

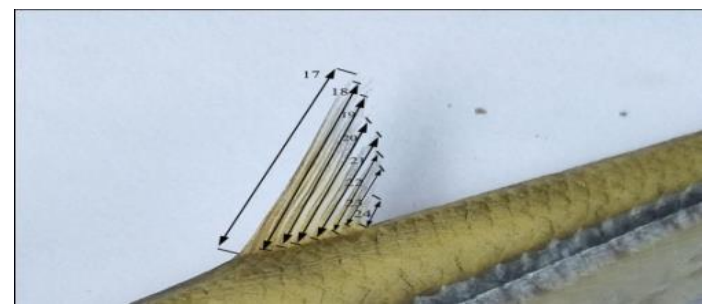


(b)

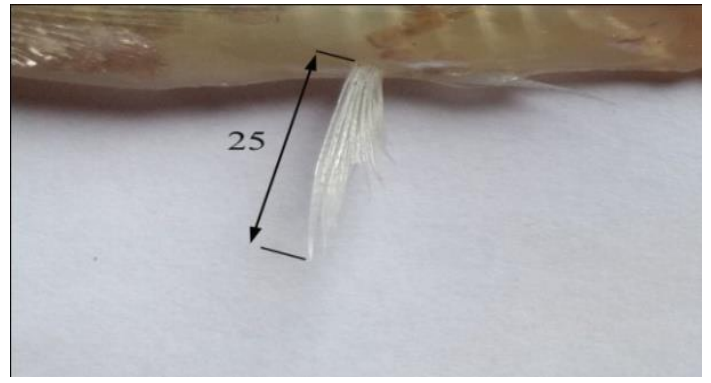

(c)

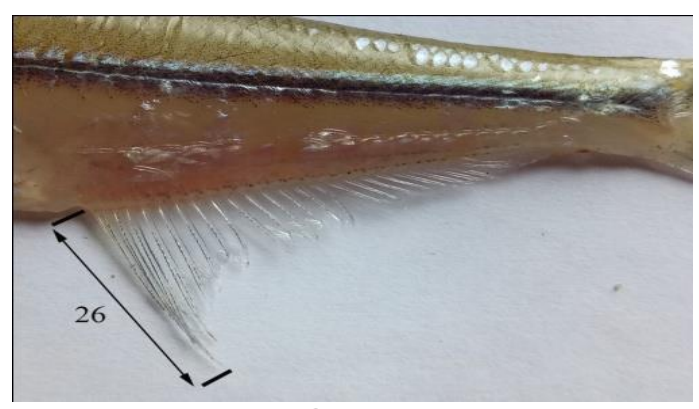

Gambar 2. Pengukuran karakter morfometrik (a)-(e).

Tabel 2. Pengukuran karakter morfometrik

\begin{tabular}{ccc}
\hline No & Karakter Morfometrik & Singkatan $(\mathbf{m})$ \\
\hline 1 & Panjang total & PT \\
2 & Panjang Standar & PS \\
4 & Panjang moncong & PM \\
5 & Diameter mata & DM \\
6 & Panjang post orbital & PPO \\
7 & Panjang Kepala & PK \\
8 & Panjang pre-pectoral & PPP \\
9 & Panjang pre-pelvik & PPV \\
10 & Panjang pre-dorsal & PPD \\
11 & Panjang pre-anal & PPA \\
12 & Panjang pangkal sirip punggung & PPSD \\
13 & Panjang pangkal sirip anal & PPSA \\
14 & Panjang sirip dada & PSP \\
15 & Panjang batang ekor & PBE \\
16 & Tinggi batang ekor & TBE \\
17 & Tinggi badan & TB \\
18 & Panjang tulang sirip punggung & PTSD1 \\
19 & pertama & PTSD2 \\
20 & Panjang tulang sirip punggung & kedua \\
& Panjang tulang sirip punggung & ketiga \\
& Panjang tulang sirip punggung & PTSD4 \\
& keempat &
\end{tabular}



kelima keenam

Panjang tulang sirip punggung ketujuh

Panjang tulang sirip punggung kedelapan

PTSD7

PTSD8

Panjang tulang sirip perut

PTSV

Panjang tulang sirip anal

PTSA

Panjang antara sirip dada ke sirip punggung punggung punggung anal anal

PSPSV

Panjang antara sirip dada ke sirip perut

Karakter meristik yang dihitung antara lain: Jumlah jari-jari sirip dorsal, jumlah jari-jari sirip anal, jumlah jari-jari sirip ventral, jumlah jari-jari sirip pektoral, jumlah jari-jari sirip caudal, jumlah sisik pada gurat sisi, jumlah sisik di atas garis rusuk (LL), jumlah sisik di bawah garis rusuk, jumlah sisik di muka sirip dorsal, jumlah sisik pada pipi, jumlah sisik sekeliling badan, jumlah sisik sekeliling batang ekor.

Tabel 2. Jenis dan jumlah ikan pimpiang yang ditemukan di sungai kumu

\begin{tabular}{|c|c|c|c|c|c|c|c|c|c|c|c|}
\hline \multirow{3}{*}{ No } & \multirow{3}{*}{ Spesies } & \multicolumn{9}{|c|}{ Jumlah individu } & \multirow{3}{*}{ Tota } \\
\hline & & \multicolumn{3}{|c|}{ Stasiun I } & \multicolumn{3}{|c|}{ Stasiun II } & \multicolumn{3}{|c|}{ Stasiun III } & \\
\hline & & 1 & 2 & 3 & 1 & 2 & 3 & 1 & 2 & 3 & \\
\hline 1 & Oxygaster anomalura & - & 1 & 2 & - & 2 & 2 & 2 & 3 & - & 12 \\
\hline 2 & $\begin{array}{c}\text { Parachela } \\
\text { oxygastroides }\end{array}$ & - & - & - & - & - & - & & - & 3 & 3 \\
\hline & Total & & 3 & & & 4 & & & 8 & & 15 \\
\hline
\end{tabular}

Keterangan: $1=$ Pengulangan 1, 2= Pengulangan 2, 3= Pengulangan 3 .

Adanya perbedaan jumlah individu dan spesies ikan pimpiang yang ditemukan pada masing-masing stasiun berkaitan dengan perbedaan kondisi fisik sungai dan faktor fisika kimia air. pengukuran faktor fisika kimia air yang

\section{HASIL}

Dari penelitian yang telah dilakukan ditemukan sebanyak 15 individu yang terdiri dari 2 spesies yang teridentifikasi sesuai dengan buku identifikasi, yaitu Oxygaster anomalura dan Parachela oxygastroides. Jenis-jenis ikan yang telah diidentifikasi ditampilkan pada Tabel 2 berikut ini. 
selama penelitian. Hal ini di dukung oleh Reni (2013: 12) yang menjelaskan, bahwa kehidupan organisme di perairan tergantung kepada ketahanan organisme tersebut. Tingginya jumlah ikan pimpiang sangat ditentukan oleh kondisi lingkungan perairan. Setiap jenis ikan agar

dapat hidup dan berkembang biak harus dapat menyesuaikan diri dengan kondisi lingkungan di mana ikan tersebut hidup.

Tabel 5. Hasil Perhitungan Parameter Fisika dan Kimia di Sungai Kumu

\begin{tabular}{ccccccc}
\hline No & Parameter & Satuan & \multicolumn{3}{c}{ Stasiun } & Rata- \\
\cline { 4 - 6 } & & & $\mathrm{I}$ & $\mathrm{II}$ & $\mathrm{III}$ & rata \\
\hline 1 & Suhu & ${ }^{0} \mathrm{C}$ & 27,66 & 27,33 & 27 & 27,33 \\
2 & $\mathrm{pH}$ & - & 5 & 5 & 5 & 5 \\
3 & Kecepatan arus & $\mathrm{m} / \mathrm{s}$ & 0,15 & 0,11 & 0,09 & 0,12 \\
4 & Kedalaman & $\mathrm{m}$ & 0,8 & 0,94 & 1,04 & 0,93 \\
\hline
\end{tabular}

\section{PEMBAHASAN}

\section{Oxygaster anomalura}

Berdasarkan hasil penelitian karakter morfologi Oxygaster anomalura memiliki ciri otot punggung tidak mencapai bidang antara dua mata, terdapat 50 sisik pada dari pangkal sirip perut, dan kepala mendongak keatas. Setelah mencoco kan dengan buku identifikasi (kottelat dkk.,

1993: 56) menyebutkan ikan yang memiliki karakteristik morfologi otot
Komposisi dan distribusi ikan sangat dipengaruhi oleh perubahan fisika, kimia dan biologi (Sriwidodo et al., 2013: 48). Pengukuran faktor lingkungan bertujuan untuk melihat pengaruh perubahan kondisi perairan terhadap komunitas sumber daya ikan. Faktor fisika dan kimia sungai Kumu Kabupaten Rokan Hulu di sajikan pada Tabel 5.

Tabel 3. Pengukuran karakter morfologi Oxygaster anomalura

\begin{tabular}{lccc}
\hline No. & $\begin{array}{c}\text { Karakter } \\
\text { Morfologi }\end{array}$ & Rata-rata $(\mathbf{m m})$ & Min-Max $(\mathbf{m m})$ \\
\hline 1 & PT & $\pm 128,23$ & $105,37-164,025$ \\
2 & PS & $\pm 99,41$ & $81,06-138,70$ \\
3 & PM & $\pm 4,49$ & $2,70-6,58$ \\
4 & DM & $\pm 5,82$ & $4,55-7,41$ \\
5 & PPO & $\pm 8,48$ & $7,12-11,74$ \\
6 & PK & $\pm 18,78$ & $15,33-25,21$ \\
7 & PPP & $\pm 26,86$ & $17,82-28,98$ \\
8 & PPV & $\pm 42,41$ & $36,19-56,99$ \\
9 & PPD & $\pm 61,05$ & $53,34-81,79$ \\
10 & PPA & $\pm 60,00$ & $41,16-83,97$ \\
11 & PPSP & $\pm 5,26$ & $3,83-6,94$ \\
12 & PPS & $\pm 24,53$ & $14,19-36,87$ \\
13 & PSD & $\pm 40,64$ & $32,45-59,97$ \\
14 & PBE & $\pm 10,06$ & $4,50-14,60$ \\
15 & TBE & $\pm 6,77$ & $4,21-11,31$ \\
16 & TB & $\pm 21,32$ & $15,14-32,89$
\end{tabular}


Agroprimatech

Vol. 3 No. 2, April 2020

e-ISSN : 2599-3232

\begin{tabular}{|c|c|c|c|}
\hline 17 & PTSD1 & $\pm 14,36$ & $10,72-17,93$ \\
\hline 18 & PTSD2 & $\pm 13,01$ & $10,15-16,77$ \\
\hline 19 & PTSD3 & $\pm 12,20$ & $10,29-15,88$ \\
\hline 20 & PTSD4 & $\pm 11,15$ & $9,67-14,66$ \\
\hline 21 & PTSD5 & $\pm 9,91$ & $7,66-13,97$ \\
\hline 22 & PTSD6 & $\pm 7,84$ & $7,07-8,64$ \\
\hline 23 & PTSD7 & $\pm 6,32$ & $5,53-7,16$ \\
\hline 24 & PTSD8 & $\pm 4,66$ & $3,76-5,87$ \\
\hline 25 & PTSV & $\pm 13,62$ & $9,92-18,07$ \\
\hline 26 & PTSA & $\pm 15,29$ & $13,31-18,51$ \\
\hline 27 & PASPSD & $\pm 41,01$ & $34,45-58,61$ \\
\hline 28 & PASDSV & $\pm 24,93$ & $18,69-38,64$ \\
\hline 29 & PASASD & $\pm 18,12$ & $13,24-28,92$ \\
\hline 30 & PASVSA & $\pm 17,48$ & $11,57-27,50$ \\
\hline 31 & PASPSA & $\pm 39,49$ & $29,33-58,26$ \\
\hline 32 & PASPSV & $\pm 22,44$ & $17,39-30,65$ \\
\hline
\end{tabular}

Karakter meristik yang didapat Oxygaster anomalura yaitu memiliki rumus sirip D.I.7, A.II.24, V.I.7, P.I.12, C.VIII.16. Jumlah sisik pada gurat sisi terdiri dari 50 , jumlah sisik pada garis rusuk terdiri dari 11, jumlah sisik di atas garis rusuk terdiri dari 8 , jumlah sisik di bawah garis rusuk terdiri dari 2, jumlah sisik muka sirip dorsal terdiri dari 40, jumlah sisik pada pipi tidak ada, jumlah sisik sekeliling badan terdiri dari 42 , jumlah sisik sekeliling batang ekor terdiri dari 18.

Berdasarkan penelitian yang telah dilakukan dari tiga stasiun penelitian bahwa rata-rata karakter morfologi Oxygaster anomalura dari tiga stasiun tidak memperlihatkan variasi yang besar. Karakter morfologi Oxygaster anomalura di stasiun satu memiliki kisaran panjang total $360,33 \mathrm{~mm}$ dengan rata-rata \pm $120,11 \mathrm{~mm}$, stasiun dua memiliki kisaran panjang total $502,34 \mathrm{~mm}$ dengan ratarata $\pm 129,34 \mathrm{~mm}$, sedangkan stasiun tiga memiliki panjang total $634,34 \mathrm{~mm}$ dengan rata-rata $\pm 135,24 \mathrm{~mm}$. Ikan pimpiang dan ikan bada mempunyai karakter morfometrik yang sama.
Purnama dkk., (2019) telah melakukan penelitian kajian karakter morfologi Rasbora Caudimaculata dengan panjang total (TL) dengan Mean \pm SD $106,88 \pm 12,5 \mathrm{~mm}$ dan Range 87,50$132 \mathrm{~mm}$.

2. Parachela oxygastroides

Parachela oxygastroides memiliki ciri jumlah sisik pada gurat sisi 43 , otot punggung mencapai bagian atas pinggiran mata bagian depan, dan lateral line sangat jelas. Setelah mencocokkan dengan buku identifikasi (kottelat dkk., 1993: 60) menyebutkan ikan yang memiliki karakteristik morfologi sisik pada gurat sisi 40-43; otot punggung memanjang mencapai bagian atas pinggiran mata bagian depan ciri tersebut merupakan spesies Parachela oxygastroides. Ciri lainnya, punggung agak datar, lateral line sangat jelas, mulai dari operculum melengkung kebawah hingga pangkal ekor (Sukmono dan Mira., 2017: 34). Pengukuran standar deviasi karakter morfologi Parachela oxygastroides dapat dilihat pada Tabel 4 berikut.

Tabel 4. Pengukuran karakter morfologi Parachela oxygastroides

\begin{tabular}{lccc}
\hline No. & Karakter Morfologi & Rata-rata $(\mathbf{m m})$ & Min-Max $(\mathbf{m m})$ \\
\hline 1 & PT & $\pm 113,14$ & $105,27-119,60$ \\
2 & PS & $\pm 90,53$ & $82,96-94,88$ \\
3 & PM & $\pm 3,11$ & $2,97-3,31$
\end{tabular}


Agroprimatech

Vol. 3 No. 2, April 2020

e-ISSN :2599-3232

\begin{tabular}{lccc}
4 & DM & $\pm 5,46$ & $4,55-7,41$ \\
5 & PPO & $\pm 8,60$ & $5,08-6,09$ \\
6 & PK & $\pm 17,17$ & $7,53-10,30$ \\
7 & PPP & $\pm 20,77$ & $16,05-18,35$ \\
8 & PPV & $\pm 41,07$ & $20,07-21,32$ \\
9 & PPD & $\pm 56,65$ & $37,84-43,44$ \\
10 & PPA & $\pm 56,29$ & $53,37-59,39$ \\
11 & PPSP & $\pm 3,43$ & $52,63-59,95$ \\
12 & PPSA & $\pm 24,11$ & $3,01-3,76$ \\
13 & PSD & $\pm 38,63$ & $21,44-28,18$ \\
14 & PBE & $\pm 8,16$ & $34,64-40,81$ \\
15 & TBE & $\pm 7,56$ & $6,73-9,16$ \\
16 & TB & $\pm 22,93$ & $7,16-7,85$ \\
17 & PTSD1 & $\pm 10,74$ & $10,42-11,32$ \\
18 & PTSD2 & $\pm 10,00$ & $9,64-10,33$ \\
19 & PTSD3 & $\pm 9,30$ & $9,20-9,40$ \\
20 & PTSD4 & $\pm 7,77$ & $6,93-8,40$ \\
21 & PTSD5 & $\pm 7,05$ & $6,39-7,98$ \\
22 & PTSD6 & $\pm 6,27$ & $5,64-7,11$ \\
23 & PTSD7 & $\pm 5,64$ & $5,28-6,33$ \\
24 & PTSD8 & $\pm 4,44$ & $4,21-4,85$ \\
25 & PTSV & $\pm 9,55$ & $8,59-10,24$ \\
26 & PTSA & $\pm 12,94$ & $12,55-13,39$ \\
27 & PSPSD & $\pm 39,91$ & $33,57-44,06$ \\
28 & PSVSD & $\pm 25,66$ & $22,78-27,62$ \\
29 & PSASD & $\pm 17,79$ & $15,68-19,04$ \\
30 & PSVSA & $\pm 13,72$ & $11,15-17,28$ \\
31 & PSPSA & $\pm 36,93$ & $31,61-40,76$ \\
32 & PSPSV & $\pm 23,01$ & $20,14-25,32$ \\
\hline & & & \\
\hline
\end{tabular}

Hasil perhitungan karakter meristik Parachela oxygastroides memiliki rumus sirip D.I.7, A.II.28, V.I.4, P.I.8, C.VI.17. Jumlah sisik pada gurat sisi terdiri dari 43, jumlah sisik pada garis rusuk terdiri dari 5, jumlah sisik di atas garis rusuk terdiri dari 7 , jumlah sisik di bawah garis rusuk terdiri dari 2, jumlah sisik muka sirip dorsal terdiri dari 43, jumlah sisik pada pipi tidak ada, jumlah sisik sekeliling badan terdiri dari 28 , jumlah sisik sekeliling batang ekor terdiri dari 14 .

\section{KESIMPULAN}

Dari penelitian yang telah dilakukan dapat diambil kesimpulan sabagai berikut yaitu ditemukan 2 spesies ikan pimpiang yang terdiri dari Oxygaster anomalura sebanyak 12 individu dan Parachela oxygastroides sebanyak 3 individu, total individu ikan pimpiang yang tertangkap sebanyak 15 individu. Karakter morfologi Oxygaster anomalura memiliki kisaran panjang total $105,37-164,05 \mathrm{~mm}$ dengan rata-rata \pm $128,23 \mathrm{~mm}$, tinggi badan 15,14-32,89 $\mathrm{mm}$ dengan rata-rata $\pm 22,40 \mathrm{~mm}$.

Sedangkan karakter morfologi Parachela oxygastroides memiliki kisaran panjang total 105,27-119,60 mm dengan rata-rata $\pm 113,14 \mathrm{~mm}$, tinggi badan 21,13-24,93 $\mathrm{mm}$ dengan rata-rata $\pm 22,93 \mathrm{~mm}$.

\section{DAFTAR PUSTAKA}

Kementerian Kelautan dan Perikanan. 2012. Ikan Air Tawar Langka di Indonesia. Jakarta.

Nelson, J. S. 2006. Fishes of the world fourth edition. Jhon Wiley and Sons Inc. Canada. 
Nursyahra. 2012. Jenis-jenis ikan yang tertangkap di batang air dingin kemrahan Balai Gadang Kecamatan Koto Tengah Padang. Jurnal Pelangi STKIP PGRI Sumbar. 4 (2): 1-14.

Rudiyanti, S. dan Astri, D. E. 2009. Pertumbuhan dan Survival Rate Ikan Mas (Cyprinus carpio Linn.) pada Berbagai Konsentrasi Pestisida Regent 0,3 G. Jurnal Saintek Perikanan. 5 (1): 39-47.

Kottelat, M., J., A. Whitten, S. N. Kartikasari dan S. Wirdjoatmojo. 1993. Freshwater Fishes of Western Indonesia and Sulawesi. Periplus Edition. (HK) In Collaboration With the Environmental Republik Indonesia. Jakarta.

Budiharjo, A. 2001. Perubahan Karakte $r$ Morfologi lkan Tawes (Barbodes gonionotus) yang Hidup di Danau Serpeng, Gunungkidul. Jurnal BIODIVERSITAS. 2 (1): 104-108.

Reni, R. A. 2013. Status Trofik Danau Rawa Pening dan Komposisi Ikan yang Hidup Bebas di Dalamnya. Skripsi. Program Studi Pendidikan Biologi Fakultas Pendidikan Matematika dan Ilmu Pengetahuan
Alam IKIP PGRI Semarang. Semarang.

Sriwidodo, D. W. E., Agung, B. dan Sugiyarto. 2013. Keanekaragaman jenis ikan di kawasan inlet dan outlet Waduk Gajah Mungkur Wonogiri. Bioteknologi. 10 (2): 4346.

Sukmono, T. dan Mira, M. 2017. Ikan Air Tawar di Ekosistem Bukit Tiga Puluh. Yayasan Konservasi Ekosistem Sistem Sumatera dan Fraktura Zoological Society.

Purnama, A. A., J. Mubarak, I. Daruwati, D. I. Roslim, R. Elvyra. 2019. Firsht report of morphological and molecular identification of greater scissortail Rasbora caudimaculata from Rokan Hulu District, Riau Province, Indonesia. AACL Bioflux. 12 (1): 34-41. 